\title{
Evolução da Percepção Discente Frente ao Uso de Videoaulas em Laboratório de Engenharia Elétrica
}

\author{
Augusto José Silva Firmo, B. Sc.* \\ * Departamento de Engenharia Elétrica, Universidade Federal de Campina Grande, Campina \\ Grande, Brasil. \\ E-mail: augusto.firmo@ee.ufcg.edu.br \\ Marcus Tulius Barros Florentino, M. Sc. \\ •Centro de Ciências Exatas e Tecnológicas, Universidade Federal do Recôncavo da Bahia, Bahia, \\ Brasil. \\ E-mail: marcus.florentino@ufrb.edu.br \\ Tarso Vilela Ferreira, D. Sc.` \\ ${ }^{`}$ Departamento de Engenharia Elétrica, Universidade Federal de Sergipe, Aracaju, Brasil. \\ E-mail: tarso@dee.ufcg.edu.br
}

\begin{abstract}
Resumo
Este artigo apresenta a experiência obtida no uso de videoaulas como ferramentas didáticas no processo ensino-aprendizagem em práticas da disciplina "Laboratório de Circuitos Elétricos I", constituinte da matriz Curricular do Curso de Graduação em Engenharia Elétrica da Universidade Federal de Campina Grande. Na época da implantação das videoaulas, em 2012, e mais recentemente, em 2015, foram realizadas consultas aos estudantes no sentido de quantificar-se o impacto desse novo recurso didático em seu aprendizado. Uma comparação entre os resultados das duas consultas é realizada, permitindo evidenciar diferenças no comportamento do corpo discente e na aprendizagem
\end{abstract}


prática em Engenharia. Além disso, evidencia-se que tais recursos podem ser utilizados em plataformas digitais de acesso público, atendendo às necessidades da comunidade externa à universidade.

Palavras-Chave: Educação, Engenharia, Ensino à Distância, Videoaulas, Laboratório.

\begin{abstract}
This work presents an experience of using video lectures as didactic tools in the teachinglearning process in the experiments of the course ?Electrical Circuits I Laboratory?, part of the curricular grid of the Electrical Engineering Undergraduate Course of the Federal University of Campina Grande. At the time of the implementation of the video lectures, in 2012, and more recently, in 2015, surveys were applied to the students in order to quantify the impact of the new didactic resource in their learning. A comparison between the results of the two surveys is carried out, showing differences in student behavior and in practical learning in engineering. In addition, it is evident that such resources can be used in digital platforms of public access, attending to the needs of the community outside the university.
\end{abstract}

Keywords: Education, Engineering, Distance Learning, Laboratory, Video Lecture.

\title{
Resumen
}

Este artículo presenta la experiencia obtenida en el uso de videoaulas como herramientas didácticas en el proceso enseñanza-aprendizaje en las prácticas de la disciplina "Laboratorio de Circuitos Eléctricos I", que hace parte de la matriz curricular del Curso de Pregrado en Ingeniería Eléctrica de la Universidad Federal de Campina Grande. En la época de la implementación de las videoaulas, en 2012, y más recientemente, en 2015, fueron realizadas consultas a los estudiantes en el sentido de cuantificar el impacto de ese nuevo recurso didáctico en su aprendizaje. Se realizó una comparación entre los resultados de las dos consultas, permitiendo evidenciar las diferencias en el comportamiento de los estudiantes y en el aprendizaje práctico en Ingeniería. Además, se verifica que tales recursos pueden ser utilizados en plataformas digitales de acceso público, atendiendo a las necesidades de la comunidad externa a la Universidad.

Palabras claves: Educación en Ingeniería, Ingeniería Eléctrica, Educación a Distancia, Videoaulas, Laboratorio. 


\section{Introdução}

Um dos maiores vetores da inovação e do desenvolvimento tecnológico constitui-se na formação de novos Engenheiros. A indústria constantemente carece de avanços que só são possíveis com a imersão de novas competências na Educação em Engenharia. Por outro lado, diversas regiões do país em pleno desenvolvimento ainda sofrem com a falta de infraestrutura e de pessoal qualificado, que desacelera este processo de desenvolvimento.

O uso de mídias digitais tem sido uma das principais apostas das instituições de ensino em Engenharia no sentido de vencer as barreiras geográficas, não só no Brasil, mas em diversos países no mundo. Vários cursos de formação tecnológica e de Engenharia têm se abrangido dentro da Educação a Distância (EaD) em um processo que vem se transformando há mais de duas décadas. Um exemplo disso é um artigo publicado por Taylor e outros (1996) na Frontiers in Education Conference, que se intitula Distance Learning in Courses With a Laboratory ${ }^{1}$. Os autores demonstraram técnicas efetivas de ensino em laboratório de Engenharia que utilizam mídias em EaD.

Algumas Universidades pelo mundo, como a Stanford University e a Pennsylvania State University, nos Estados Unidos, além da University of Queensland, na Austrália, já adotam videoaulas em grande parte dos planos de curso das disciplinas e oferecem cursos inteiramente à distância ${ }^{2-4}$. No Brasil, cursos como o de Engenharia Civil da Universidade Federal do Rio Grande do Sul, na área de Geotécnica, e como o de Engenharia Elétrica da Universidade Federal de Juiz de Fora, utilizaram videoaulas e plataformas computacionais na EaD de maneira satisfatória ${ }^{5}$. A Universidade de São Paulo oferece uma plataforma online, denominada e-Aulas, onde podem ser encontradas videoaulas que abrangem diversos temas e cursos ofertados para estudantes e a comunidade ${ }^{6}$.

Estudos no campo da Educação de Engenharia apontam para tendências na utilização em larga escala das tecnologias de informação e comunicação para aprimorar o processo ensino-aprendizagem. Isto é esperado pelo fato destas tecnologias aumentarem a acessibilidade dos estudantes aos conteúdos de Engenharia, como também permitirem grande flexibilidade em termos de como, quando e onde estudar ${ }^{7}$. Segundo Tudevdagva (2014), a ideia de criar e usar técnicas de EaD no ensino da Engenharia tem ampla possibilidade de melhorar a qualidade de ensino, podendo ser utilizadas em laboratórios como um novo tipo de tecnologia ${ }^{8}$.

Paralelamente, percebe-se que a garantia da qualidade de ensino nas Universidades brasileiras está se tornando, cada vez mais, um desafio para os professores. Os motivos estão relacionados à quantidade de aulas lecionadas nas disciplinas, ao número de alunos matriculados, à falta de laboratórios ou a sua atualização e à falta de espaços físicos adequados para as atividades de ensino ${ }^{9}$.

Uma das maiores dificuldades da EaD em Engenharia está na necessidade de aulas práticas de laboratório, que requerem espaço físico adequado. Entretanto, em locais atendidos por essa infraestrutura ainda existem necessidades de atualização do processo didático. Além disso, com a crescente inserção de alunos na rede pública de ensino superior do Brasil mediante programas de inclusão, torna-se cada vez mais necessário o uso de ferramentas que aproximem professor e aluno.

O uso de mídias digitais e da internet atende às demandas estabelecidas: pode ser empregado em cursos com e sem carência de infraestrutura e regióes com pouca oferta de qualificação, além de se constituir em uma maneira dinâmica e instantânea de aproximar aluno e professor fora da sala de aula.

Neste trabalho é apresentada a experiência da aplicação de videoaulas em uma disciplina prática, o Laboratório de Circuitos Elétricos I (LCEI), constituinte da estrutura curricular 
do Curso de Engenharia Elétrica da Universidade Federal de Campina Grande. Apesar de ser um curso presencial, o LCEI não tem carga horária reservada para aulas expositivas, de maneira que as videoaulas vieram proporcionar aos estudantes contato complementar com o instrumental do laboratório, métodos e procedimentos.

A fim de viabilizar a execução da pesquisa, tomaram-se como janelas de observação duas turmas em semestres distintos, uma em 2012 e outra em 2015. A percepção dos estudantes nestas duas ocasiões foi quantificada por meio da aplicação de questionários, permitindo assim uma comparação direta e constatação das diferenças entre as experiências.

\section{A Educação a Distância no Brasil: de 2012 e 2015}

A Lei de Diretrizes e Bases da Educação ( $n^{\circ}$ 9.394/1996), dentre outras regulamentações, disciplina o uso de plataformas EaD nos diversos níveis de ensino e formação ${ }^{10}$. Já o Plano Nacional de Educação (PNE) é o documento que norteia as ações de desenvolvimento da educação no Brasil. Na lei do PNE ( $n^{\circ}$ 13.005/2014), dentre outras diretrizes estão a universalização do atendimento escolar, a melhoria da qualidade da educação e a promoção humanística, científica, cultural e tecnológica do País ${ }^{11}$. Essas três diretrizes servem como base para o desenvolvimento de soluções didáticas que apresentem inovação tecnológica e universalização do ensino.

Baseados nesses direcionamentos, diversos programas vêm se desenvolvendo em Universidades brasileiras no sentido de sedimentar o Ensino à Distância dentro das propostas correspondiam dos cursos de graduação e pós-graduação ${ }^{12,13}$. Essa tendência se justifica também pela popularização do acesso à internet, que é um ambiente ideal para a divulgação e crescimento da EaD. Segundo da Silva Filho (2011), mais de 200 instituições de ensino superior no Brasil atuam de alguma forma em Educação à Distância ${ }^{13}$. Esse número indica uma maior aceitação dos novos recursos que a EaD traz ao Ensino Superior.

De acordo com a Associação Brasileira de Educação a Distância (ABED), em 2012, foram 252 participantes dentre instituições formadoras, prestadores de serviços e professores livres no censo da EaD no Brasil. Das 231 instituições de ensino que participaram do censo, $67 \%$ eram das regiões Sul e Sudeste, mas houve um destaque para a região Norte que cresceu sua participação entre os anos de 2010 e 2012. Além disso, o perfil traçado para o mesmo ano evidencia a participação massiva de instituições de grande porte em cursos de formação superior. A quantidade de cursos ofertados dentro do grupo de instituições participante do censo foi de 9.376 (3,4\% a mais que 2011), sendo que pouco mais de $80 \%$ eram cursos livres e cerca de $20 \%$ eram cursos autorizados ou reconhecidos formalmente. Notadamente, o maior percentual de matrículas em EaD foi em cursos livres, representando $74,4 \%$ do total de 5.772.466 de alunos matriculados no ano de $2012^{14}$.

Do total de cursos autorizados ofertados nos anos de 2012 e 2013, cerca de $2,5 \%$ correspondiam aos cursos de Engenharia. Em 2013, o censo da ABED fez um destaque aos cursos de Engenharia, principalmente Engenharia Civil, Engenharia Elétrica e Engenharia de Produção, áreas consideradas relativamente novas em EaD. A média de alunos por curso, em Engenharias, foi de 442,9, uma das mais altas no grupo de instituições avaliadas. A razão desse número está no aumento da demanda por formação tecnológica que é justificada pelas projeções do Instituto de Pesquisa Econômica e Aplicada (IPEA): até 2020, 660 mil novas vagas em Engenharia surgirão no Brasil ${ }^{15}$. Entretanto, a quantidade de vagas ofertadas não corresponde às necessidades. O Brasil ainda possui déficit de formação de Engenheiros, ficando muito abaixo de países como China, Austrália e Coreia do Sul.

Embora não se tenha informações conclusivas acerca do aumento de matrículas em EaD no ano de 2013, os investimentos no setor cresceram em média $35 \%$, de acordo com $51,5 \%$ das 
instituições respondentes ${ }^{15}$. Em 2014, $51 \%$ das instituições afirmaram que os investimentos cresceram em relação ao ano anterior em no mínimo $25 \%$. Além disso, $56 \%$ das instituições respondentes projetaram aumentos nos investimentos para os anos seguintes ${ }^{16}$. Em 2015, $35,6 \%$ das instituições formadoras revelaram que os investimentos permaneceram iguais ao ano anterior. Entretanto, 11,69\% instituições responderam que os investimentos cresceram em até $25 \%$ e $4,6 \%$ revelaram que os investimentos cresceram entre $26 \%$ e $50 \%$. Por outro lado, $5,97 \%$ das instituições revelaram que os investimentos diminuíram em, no mínimo, $25 \%{ }^{17}$.

Um total de 339 instituições participaram do censo da ABED em 2015. Comparado ao ano anterior, em que 271 instituições participaram da pesquisa, o aumento foi de $25,1 \%$. Dentro desse cenário, houve um aumento da participação de Instituições Federais de Ensino Superior (IFES) em torno de $22 \%{ }^{17}$. Estas instituições são referenciais para este trabalho no que concerne o uso de ferramentas em EaD nos cursos de graduação, principalmente de pós-graduação. Dentre as IFES com projetos voltados a EaD, destacam-se no Nordeste: Universidade Federal de Pernambuco (UFPE EaD), o Instituto Metrópole Digital (IMDUFRN), Universidade Federal do Ceará (UFC Virtual), Universidade Federal de Campina Grande (UFCG Virtual) dentre outros polos.

Alguns programas de EaD nas IFES estão vinculados à Universidade Aberta do Brasil (UAB), que é voltada à população que possui dificuldade de acesso à formação universitária de forma presencial. Primordialmente, são oferecidos cursos de formação continuada às categorias de profissionais que atuam nas esferas estaduais e municipais, principalmente professores $^{18}$. Embora o programa UAB tenha sido criado em 2006 (Decreto $n^{\circ} 5.800 / 2006$ ), ele ainda está em plena expansão e ainda requer aceitação por grande parte da comunidade acadêmica. Dessa maneira, as Universidades ainda necessitam se aproximar mais da comunidade e atender às demandas que ela possa suprir além da formação superior tradicional.

\section{Elaboração de videoaulas, disponibilização de videoau- las e aplicações de Pesquisa de Opinião}

Para verificar a evolução da percepção discente ao uso de videoaulas no LCEI do curso de Engenharia Elétrica, o procedimento de elaboração de videoaulas precisa ser cuidadosamente planejado a fim de atingirem-se os objetivos desejados. Um dos aspectos mais importantes considerado é o tempo final do vídeo. É didaticamente desejável que o estudante obtenha as informações de caráter prático de forma objetiva, por isso os vídeos tendem a ser curtos. Atividades mais longas foram divididas em parcelas e originaram vídeos menores. Além disso, as videoaulas devem ser disponibilizáveis de forma relativamente independente da plataforma de vídeo online e das restrições de duração do vídeo que as mesmas possam vir a impor.

Dessa forma, dois conjuntos de videoaulas foram elaborados com as mesmas finalidades e versando sobre os mesmos conteúdos, entretanto, foram realizados em anos letivos distintos, em 2012 e em 2015, e com características de elaboração distintas. Com um formato experimental, o primeiro conjunto não utilizou métodos de roteirização, apenas a experiência didática do professor. Por outro lado, foram tomados os cuidados necessários com iluminação, disposição de componentes, voz e edição. O segundo conjunto adotou, ordenadamente, a seguinte metodologia no processo de criação:

- Criação de roteiros: com base nos conteúdos disponibilizados em cada etapa da disciplina, divididas por experimentos práticos, foram elaborados os roteiros de cada uma das videoaulas, que versaram sobre os aspectos gerais dos experimentos ou sobre pro- 
cedimentos específicos;

- Pré-produção: foram avaliados aspectos técnicos de gravação como o posicionamento da câmera, disposição dos componentes e enquadramento das montagens, iluminação e voz;

- Gravação dos vídeos: os vídeos foram gravados no mesmo espaço e com o mesmo material utilizado pelos estudantes para a realização dos experimentos. Cada vídeo foi gravado em tomadas de acordo com as etapas descritas pelos roteiros; e

- Edição dos vídeos: para finalizar os vídeos foram realizados os cortes, remoção de erros, seleção das melhores tomadas, adição de figuras, destaques, legendas e equações.

Ambos os conjuntos foram disponibilizados na plataforma Youtube.com após o processo de edição e finalização.

A primeira pesquisa de opinião foi realizada em 2013 com 41 alunos que tiveram acesso ao primeiro conjunto de videoaulas e que cursaram a disciplina nos períodos letivos de $2012^{18}$. A segunda pesquisa de opinião foi realizada em 2015 com 35 alunos que tiveram acesso aos dois conjuntos de videoaulas desenvolvidos ${ }^{19}$.

O questionário estruturado utilizado nas duas Pesquisas de Opnião é apresentado no Quadro 1.

Quadro 1 - Questionário estruturado da Pesquisa de Opinião.

- As videoaulas ajudaram no seu aprendizado?

- A explicação dada foi satisfatória?

- As videoaulas permitiram uma melhor familiarização com os instrumentos de medição?

- O acesso às videoaulas é facilitado?

- Você considera as videoaulas como um método complementar eficiente de preparação para os experimentos do laboratório?

- As videoaulas responderam alguma(s) de suas dúvidas antes e durante a realização dos experimentos?

Você considera importante o uso de videoaulas nos demais laboratórios da Graduação em Engenharia Elétrica?

\section{Resultados}

Um comparativo sobre os principais resultados obtidos em ambos as pesquisas é apresentado nas figuras 1 a 7 . A primeira versão (em roxo escuro) refere-se à turma de $2012^{18} \mathrm{e}$ a segunda versão (em roxo claro) refere-se à turma de $2015^{19}$. 
- Primeira Versão $\quad$ Segunda Veresão

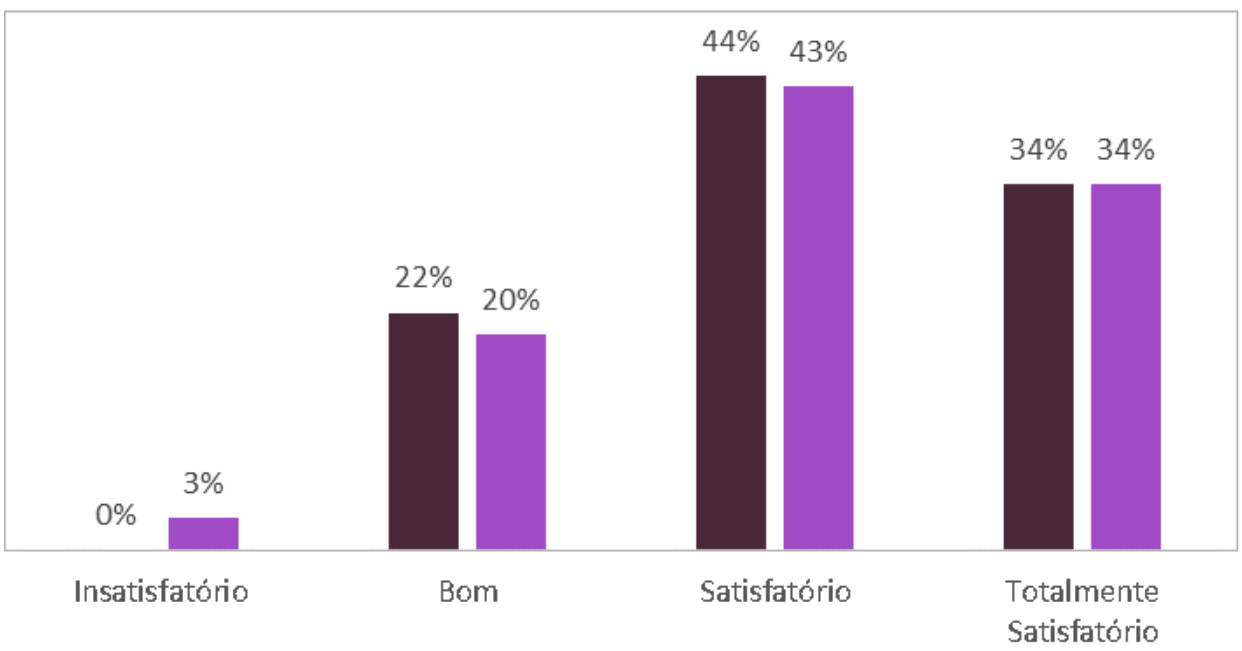

Figura 1.Gráfico referente ao aprendizado dos alunos.

- Primeira Versão $\quad$ Segunda Veresão

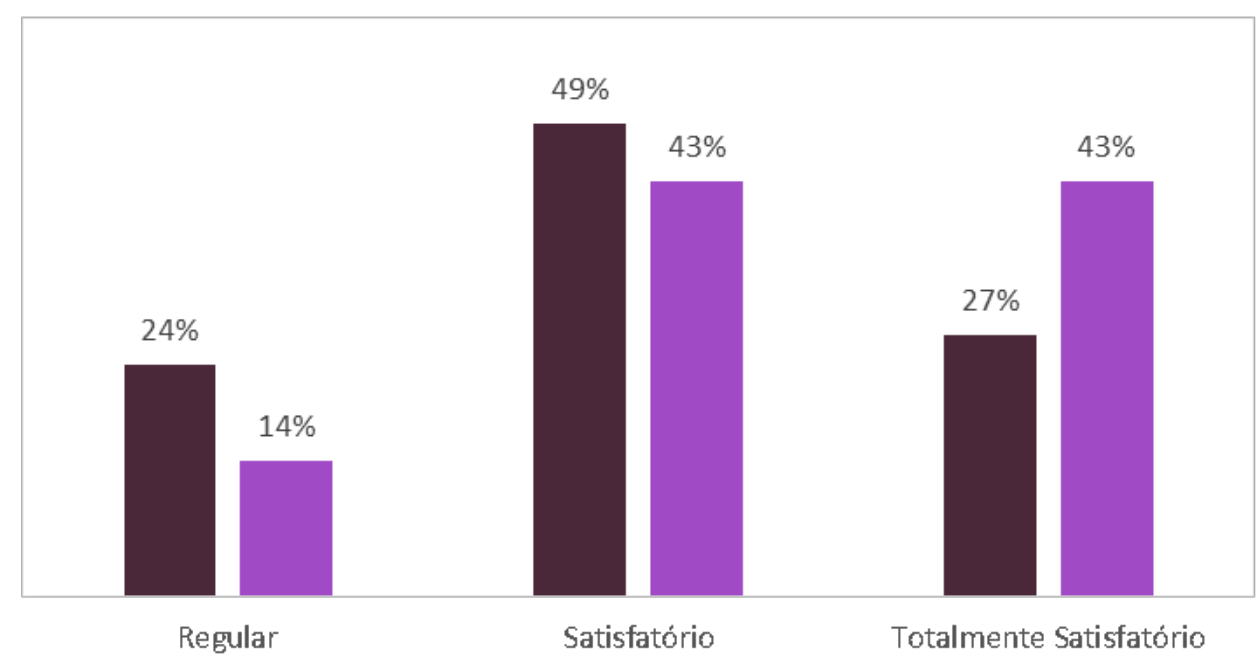

Figura 2.Gráfico referente à explicação fornecida. 
- Primeira Versão $\quad$ Segunda Veresão

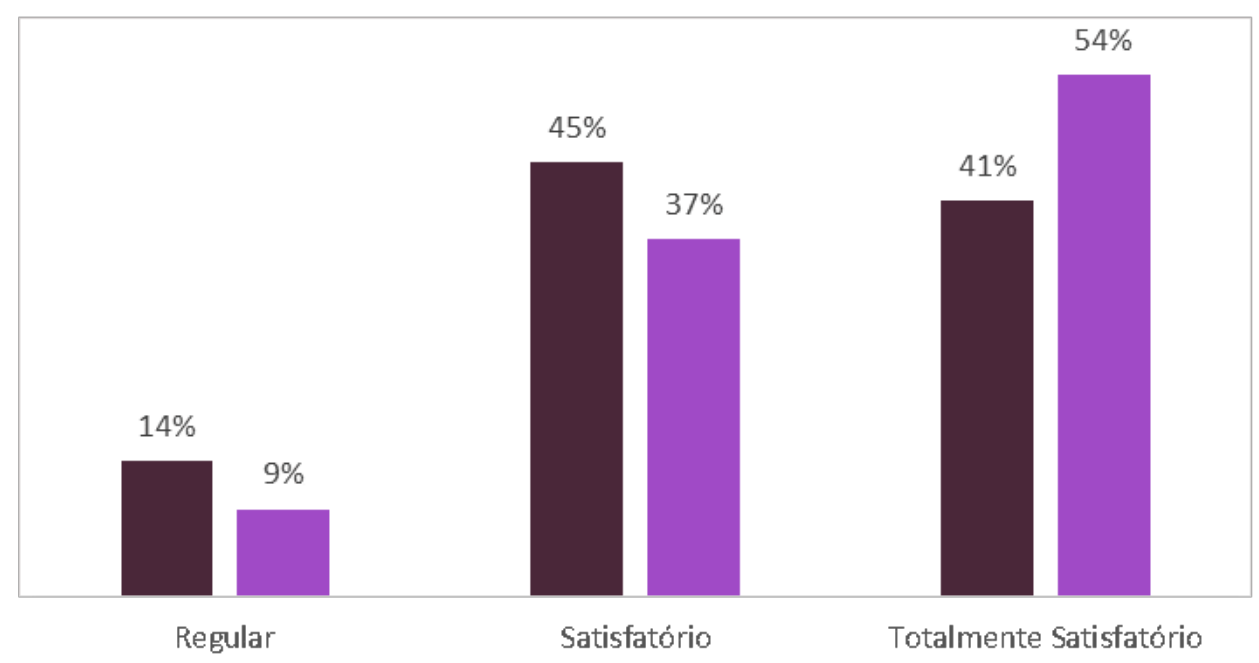

Figura 3.Gráfico referente a familiarização com os instrumentos de medição.

- Primeira Versão $\quad$ Segunda Veresão

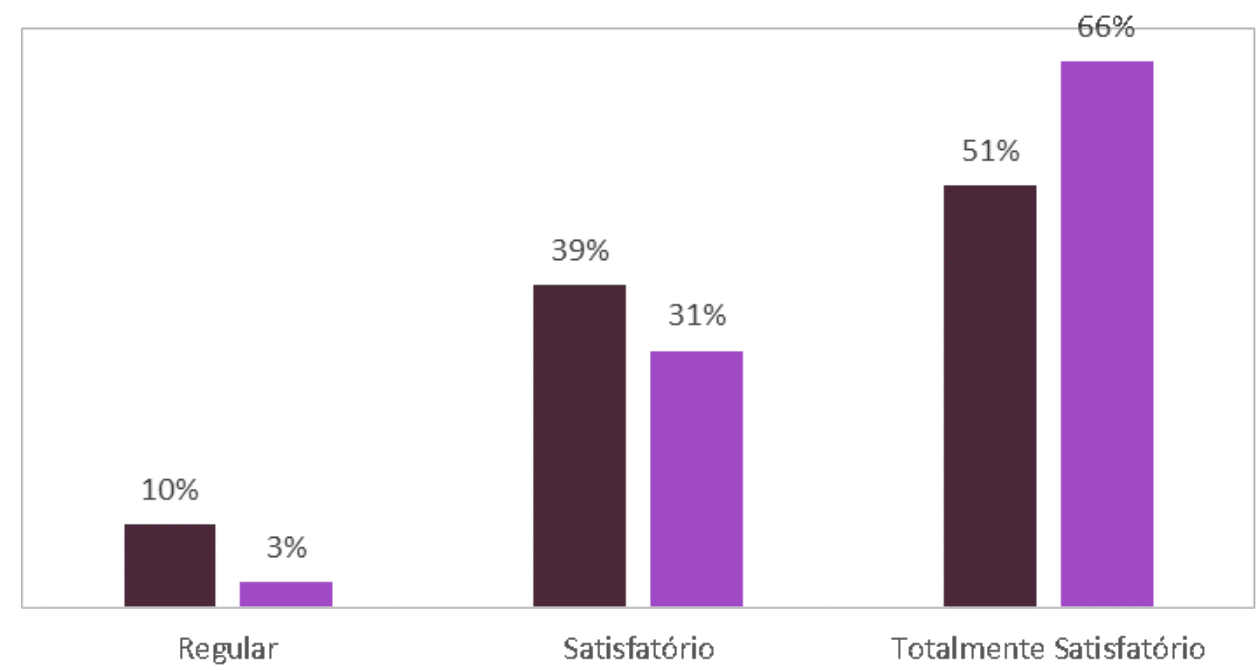

Figura 4.Gráfico referente à facilidade de acesso. 
- Primeira Versão $\quad$ Segunda Veresão

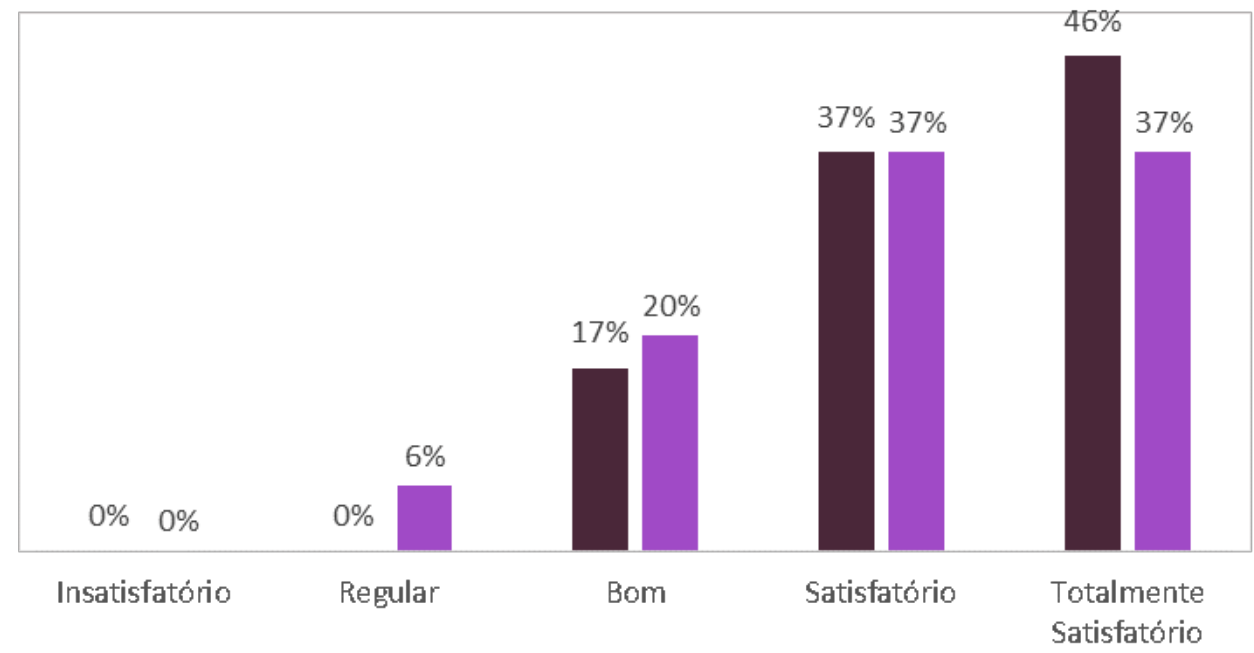

Figura 5.Gráfico referente ao método complementar eficiente.

- Primeira Versão — Segunda Veresão

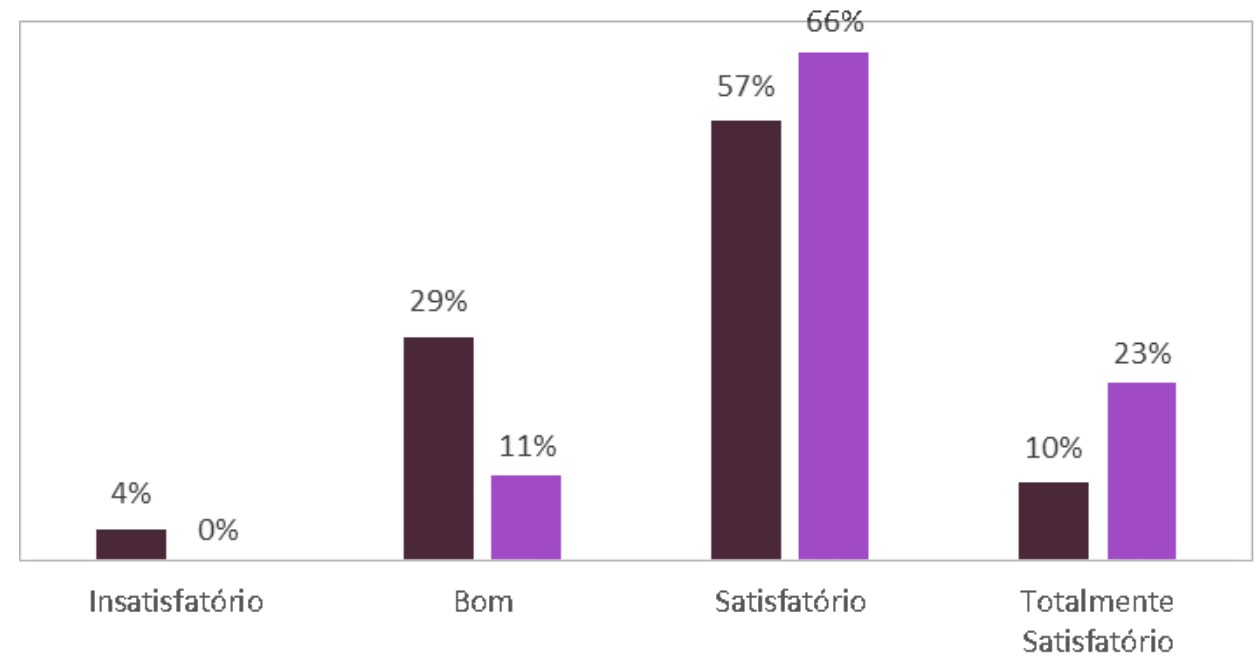

Figura 6. Gráfico referente às dúvidas respondidas. 


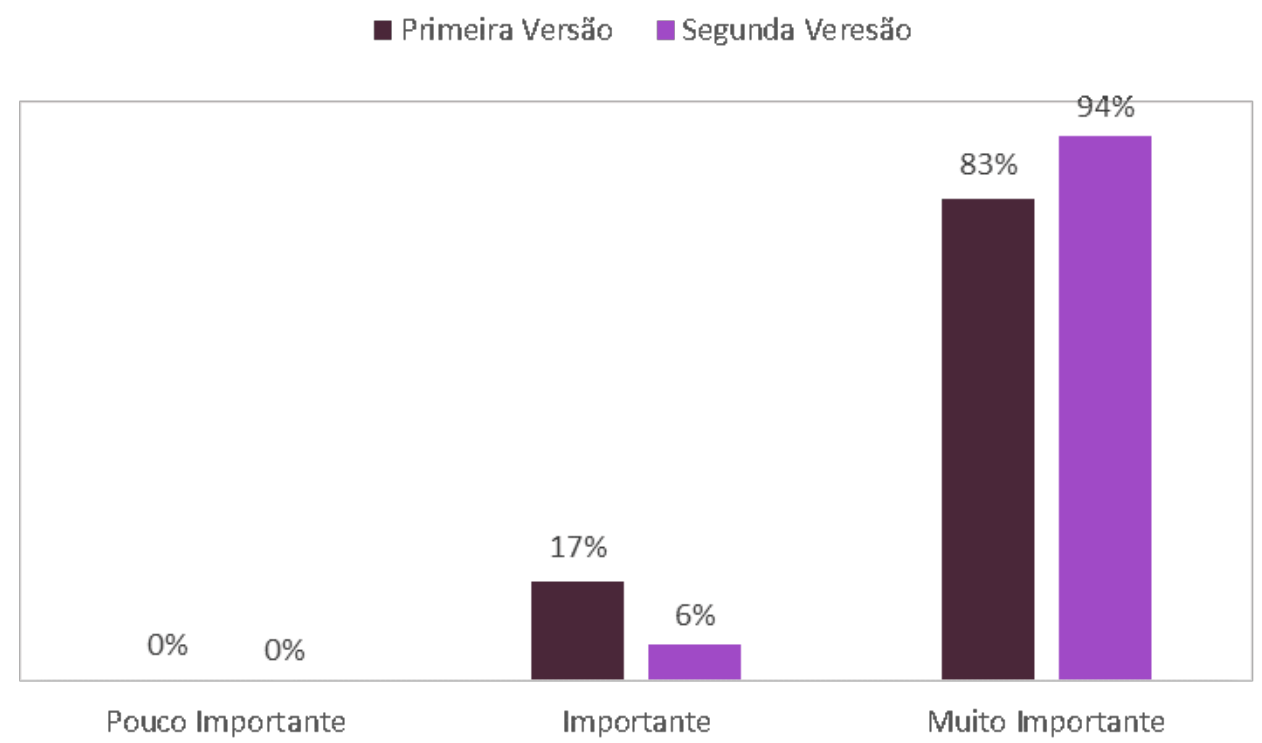

Figura 7.Gráfico referente à importância do uso em outros laboratórios da Graduação de Engenharia Elétrica.

Na Figura 1 são apresentados resultados obtidos relativamente à ajuda que as videoaulas proporcionaram no aprendizado da disciplina. Percebe-se mudanças em torno de $2 \%$, o que leva a inferir que neste aspecto, as diferenças entre os modelos usado na primeira e segunda versão não causou muitas mudanças. De certa forma este comportamento não foi surpreendente, já que conteúdo das duas versões era similar, e as diferenças no processo de produção são majoritariamente transparentes no produto final (e aos estudantes).

Na Figura 2 são apresentados os resultados obtidos em relação à satisfação dos alunos quanto a explicação fornecida nas videoaulas. Note um aumento de $16 \%$ no critério totalmente satisfatório no resultado obtido na segunda versão em relação à primeira. Este resultado pode ser atribuído a metodologia mais robusta adotada na segunda versão, utilizando criação de roteiros e realização de pós-produção dos vídeos, buscando um melhor entendimento dos alunos.

Na Figura 3 são apresentados os resultados obtidos em relação à satisfação dos alunos quanto a ajuda com a familiarização com os instrumentos de medição que as videoaulas permitiram. Note um aumento de $13 \%$ no critério totalmente satisfatório no resultado obtido na segunda versão em relação a primeira. Este comportamento pode ser atribuído às etapas de pré-produção realizadas antes das gravações, nas quais eram buscados melhores enquadramentos e iluminação, permitindo uma melhor observação do manuseio dos instrumentos de medição aos alunos ao assistirem as videoaulas.

Na Figura 4 são apresentados os resultados obtidos em relação a facilidade de acesso as videoaulas por parte dos alunos. Note um aumento de $15 \%$ no critério totalmente satisfatório no resultado obtido na segunda versão em relação a primeira. Como a forma de distribuição das duas versões foi a mesma (canal no Youtube), este aumento pode ser atribuído à maior familiaridade do corpo discente com a metodologia. É possível que, para a turma de 2015, 
aprender através de videoaulas seja algo mais natural que para a turma de 2012.

Na Figura 5 são apresentados os resultados obtidos em relação aos alunos considerarem as videoaulas um método eficiente de preparação para os experimentos do laboratório. Note um decréscimo de $9 \%$ no critério totalmente satisfatório no resultado obtido na segunda versão em relação a primeira. De maneira geral, as duas versões conseguem um resultado satisfatório quanto a ser um método eficiente de preparação para os experimentos, sendo obtido um total de $83 \%$ nos critérios totalmente satisfatório e satisfatório na primeira versão e $74 \%$ na segunda versão nos mesmos critérios.

Na Figura 6 são apresentados os resultados obtidos em relação às dúvidas dos alunos respondidas antes e durante a realização do experimento que foram respondidas pelas videoaulas. Note um aumento de $13 \%$ no critério totalmente satisfatório no resultado obtido na segunda versão em relação a primeira. Novamente este aumento deve-se a metodologia adotada na segunda versão, pois a criação dos roteiros foi feita levando em consideração as principais dúvidas observadas pelos monitores e professor da disciplina ao longo dos períodos letivos.

Na Figura 7 são apresentados os resultados obtidos relativamente à importância do uso de videoaulas nos demais laboratórios da Graduação em Engenharia Elétrica. Note um aumento de $11 \%$ no critério muito importante no resultado obtido na segunda versão em relação a primeira. Este comportamento pode ser atribuído tanto à melhoria que pode ser vista na satisfação geral dos alunos relativamente às videoaulas apresentadas para complementação do conteúdo abordado na disciplina, como também ao aumento do uso de videoaulas por parte dos estudantes, dado que o cenário de videoaulas no Brasil vem se expandindo entre as duas janelas de observação (2012-2015).

\section{Conclusões}

Os resultados das Pesquisas de Opinião demonstram um aumento na satisfação geral dos alunos as videoaulas apresentadas na segunda versão. Isso é devido, principalmente, às mudanças de metodologia adotadas na segunda versão em relação a primeira. Além de terem sido produzidas com mais passos metodológicos, a segunda versão das videoaulas empregou tempos mais curtos, mais objetividade e dinamismo, contemplando diversos experimentos da disciplina, causando maior engajamento dos alunos.

A pré-produção adotada nas gravações da segunda versão permitiram maior padronização das videoaulas, o que melhora a absorção dos conteúdos explicados nas mesmas pelos alunos. A criação de roteiros levando em consideração as dúvidas recorrentes aos alunos observadas durante o curso ao longo dos períodos letivos, tornam as videoaulas mais atrativas aos alunos durante a preparação para os experimentos da disciplina.

Nos resultados apresentados na Figura 7 percebe-se um aumento na importância dada pelos alunos no uso de videoaulas em outros laboratórios da Graduação de Engenharia Elétrica, onde $94 \%$ destes acham isto muito importante. Isso mostra a grande aceitação das videoaulas disponibilizadas para a disciplina de Laboratório de Circuitos Elétricos I, tornando a discussão sobre videoaulas no ensino da Engenharia algo mais valoroso, já que pode trazer diversos benefícios tanto para alunos como para professores.

\section{Agradecimentos}

Os autores agradecem aos estudantes do curso de Engenharia Elétrica da UFCG que prontamente responderam aos questionamentos que formaram os resultados deste trabalho. Igualmente, ao público que somou mais de 40 mil visualizações no canal da disciplina no 
Youtube.com.

\section{Referências}

1. TAYLOR, K. D.; HONCHELL and W, J. W.; DeWitt, E. Distance Learning in Courses with a Laboratory. Em :ANNUAL CONFERENCE ON FRONTIERS IN EDUCATION,26., 1996, Salt Lake City. Proceedings... Salt Lake City: USA, 1996. Disponível em: $<$ http://ieeexplore.ieee.org/stamp/stamp.jsp?tp=\&arnumber $=567984>$. Acesso em: 24 Aug. 2017.

2. Portal da Stanford University. Stanford Online. Disponível em: < online.stanford.edu $>$. Acesso em: 07 novembro 2016.

3. Portal da The Pennsylvania State University. World Campus. Disponível em: $<$ www.worldcampus.psu.edu $>$. Acesso em: 07 novembro 2016.

4. Portal da The University of Queensland. Essencial Information for Students. Distance learning. Disponível em: <www.uq.edu.au/myadvisor/distance-learning $>$. Acesso em: 07 novembro 2016.

5. TIMM, M. I.; SCHNAID, F.; FERREIRA FILHO, R. C. M. Ensino Tecnológico: modelo de uso de multimídia e internet. Disponível em: $<$ http://www.cinted.ufrgs.br/videoeduc/modelo_ead_ensino_tecnologico_FINAL_SUCESU.pdf $>$. Acesso em: 07 novembro 2016.

6. Portal e-Aulas da Universidade de São Paulo. Disponível em: <eaulas.usp.br/portal/home >. Acesso em: 07 novembro 2016.

7. GONZÁLEZ, M. J. Integranting digital vídeo resources in teaching elearning engeneering courses. Universidad de Burgos. Espanha, 2010.

8. TUDEVDAGVA, U. The virtual laboratories: case study in traditional teaching and E-learning for engineering sciences. Power Engineering School of Mongolian University of Science and Technology. Mongolia, 2014.

9. GUEdeS, C. P. G.; ARAÚJO, J. F.; SilvA, J. P. S.; COSTA, E. G.; AlmeiDA, E. G. J. C. Estratégia para melhoria do aprendizado em disciplinas com laboratório. Em: ANAIS: XL - CONGRESSO BRASILEIRO DE EDUCAÇÃO EM ENGENHARIA. 2012, Belém. PA, 2012. Disponível em: $<$ http://198.136.59.239/ abengeorg/CobengeAnteriores/2012/artigos/103878.pdf>. Accessed on: 14 sept. 2017.

10. Lei de Diretrizes e Bases da Educação (LDB) - Brasil. Disponível em: <planalto.gov.br/ccivil_03/Leis/L9394.htm>. Acesso em: 24 de novembro de 2016.

11. PNE em Movimento. Planos da Educação - MEC. Disponível em: < pne.mec.gov.br/planos-deeducacao $>$. Acesso em: 24 de novembro de 2016.

12. Resolução CNE/CES No 1 , de 3 de abril de 2001 - Ministério da Educação do Brasil. Disponível em: < portal.mec.gov.br/dmdocuments/rces001_01.pdf>. Acesso em: 24 de novembro de 2016.

13. SILVA FILHO, A. S. Estatísticas e Retrospectos da Educação à Distância no Brasil. Revista de Educação, vol. XII, n. 14, p. 165-179, 2009. Disponível em: $<$ http://www.pgsskroton.com.br/seer/index.php/educ/article/viewFile/1888/1793>Acesso em: 14 set. 2017.

14. Censo EaD Brasil 2012. Associação Brasileira de Educação a Distância - ABED. Disponível em: <abed.org.br/censoead/censoEAD.BR_2012_pt.pdf>. Acesso em: 24 nov. 2016.

15. Censo EaD Brasil 2013. Associação Brasileira de Educação a Distância - ABED. Disponível em: $<$ abed.org.br/censoead2013/CENSO_EAD_2013_PORTUGUES.pdf $>$. Acesso em: 24 nov. 2016.

16. Censo EaD Brasil 2014. Associação Brasileira de Educação a Distância - ABED. Disponível em: <abed.org.br/censoead2014/CensoEAD2014_portugues.pdf>. Acesso em: 24 nov. 2016.

17. Censo EaD Brasil 2015. Associação Brasileira de Educação a Distância - ABED. Disponível em: $<$ http://abed.org.br/arquivos/Censo_EAD_2015_POR.pdf $>$. Acesso em: 24 nov. 2016.

18. FlOREnTinO, M. T. B.; ARAÚJO, J. F.; FERREIRA, T. V. O Uso de Vídeo-Aulas nos Laboratórios de Ensino de Graduação em Engenharia Elétrica. Em: ANAIS: XLI - CONGRESSO BRASILEIRO DE EDUCAÇÃ̂ EM ENGENHARIA. 2013, Gramado. RS, 2013. Disponível 
ISSN: 2358-1271. Int. J. of Alive Eng. Educ. (IJAEEdu). (Online). Goiânia, v. 4, n. 1, p. 45-58, jan./june 2017.57

em: $<$ http://www.fadep.br/engenharia-eletrica/congresso/pdf/117413_1.pdf $>$. Acesso em: 14 set. 2017.

19. FIRMO, A. J. S.; FERREIRA, T. V. Emprego de Vídeo-Aulas como Ferramenta Didática no Ensino Prático de Engenharia Elétrica. Em: ANAIS: XLIV - CONGRESSO BRASILEIRO DE EDUCAÇÃO EM ENGENHARIA. 2016, Natal, 2016. Disponível em: $<$ http://198.136.59.239/ abengeorg/cobenge-2016/anais/anais/156959.pdf $>$. Acesso em: 14 set. 2017. 
